\title{
Short Term Outcomes of Coronary Artery Bypass Grafting and Concomitant Valve Procedure: A Retrospective Review
}

\author{
Authors \\ Dr Amit Kumar Agarwal, Mch CTVS, Dr Kunwar Sidharth Saurabh, Mch CTVS, \\ Dr Ajit Kumar Padhy (Asst. Proff. CTVS), Dr Anubhav Gupta, Professor and H.O.D \\ Dept of Cardiothoracic Surgery, VMMC and Safdarjung Hospital, New Delhi 110049 \\ *Corresponding Author \\ Dr Khushwant Popli (Asst Prof) \\ Dept of CTVS VMMC and Safdarjung Hospital New Delhi.110049, India
}

\section{Introduction}

Rheumatic heart disease is the most common etiology for valve replacements in India. Elderly patients presenting for valve replacements may have concomitant coronary artery disease. Various studies have reported an estimated 20-40\% prevalence of CAD in patients undergoing valve replacements. Patients for valve replacement with concomitant CAD if left untreated reduces survival $^{[1]}$. Lytle et al., ${ }^{[2]}$ observed operative mortality of patients with both CAD and valvular lesion was higher if CAD was left untreated. Karp et.al ${ }^{[1]}$ recommend that complete revascularization is superior to no revascularization in patients with valvular heart disease and CAD. Previous reports have shown higher risk of combined valve and bypass procedures ${ }^{[3]}$ but with the improvements in surgical techniques and myocardial protection strategies, perioperative mortalities have shown a declining trend ${ }^{[4]}$. In this study, we retrospectively analyzed outcomes of combined procedures done in our institute.

\section{Materials and Methods}

As per our institutional protocol all patients above 40 years of age underwent coronary angiography routinely to rule out concomitant $\mathrm{CAD}$. Additional coronary artery bypass grafting $(\mathrm{CABG})$ was done in patients with significant stenosis (>70\%) of any of the major arteries. Between January 2014 to December 2018, all the patients who underwent valve replacements with concomitant CABG were included in the study. Data were collected retrospectively from the medical records. Twentyfive $(n=25)$ patients underwent combined valve replacement and CABG. The mitral valve was replaced in 15 patients, the aortic valve in 8 , and both mitral and aortic valves were replaced in 2 . Patient characteristics are mentioned in table 1.

\section{Clinical Data}

In our study population, $64 \%$ were male and $36 \%$ were female with a mean age of $58.33 \pm 4.7$ years. Preoperatively $76 \%$ were in NYHA class III-IV with $12 \%$ presenting with congestive failure. Atrial fibrillation was present in $52 \%$ of patients. 
Most common mitral valve lesion was mitral stenosis due to rheumatic heart disease. Severe pulmonary hypertension was more commonly associated with mitral lesions. Diabetes and hypertension were more common in patients presenting with triple vessel disease. One patient had chronic empyema and 2 patients had Chronic obstructive pulmonary disease. Single vessel disease was present in $32 \%$ of cases, double vessel in $52 \%$ of cases and triple vessel disease was present in $16 \%$ of cases. We did not encounter any patient with significant left main stenosis. Mitral valve was involved alone in $60 \%(n=15)$ of cases whereas aortic valve was involved in $32 \%(\mathrm{n}=8)$ of cases and combined lesions were present in $8 \%(n=2)$ of cases

Table 1 Patient Characteristics $(n=25)$

\begin{tabular}{|l|c|}
\hline Female & $9(36 \%)$ \\
\hline Male & $16(64 \%)$ \\
\hline Mean age & $58.33+/-4.87$ \\
\hline NYHA 1-2 & $6(24 \%)$ \\
\hline NYHA 3-4 & $19(76 \%)$ \\
\hline LVEF $\leq 40 \%$ & $11(44 \%)$ \\
\hline LVEF>40\% & $14(56 \%)$ \\
\hline Type2 Diabetes & $7(28 \%)$ \\
\hline Hypertension & $5(20)$ \\
\hline Atrial Fibrillation & $13(52 \%)$ \\
\hline Severe Pulmonary Hypertension & $6(24 \%)$ \\
\hline CHF & $4(16 \%)$ \\
\hline Comorbities & $3(12 \%)$ \\
\hline
\end{tabular}

\section{Operative Data}

\begin{tabular}{|l|c|}
\hline & No of pts \\
\hline CABG+MVR & 15 \\
\hline CABG+AVR & 8 \\
\hline CABG+DVR & 2 \\
\hline MEAN NO OF GRAFTS & $1.91 \pm 0.69$ \\
\hline Mean cross clamp time & $116.1 \pm 23.3 \mathrm{~min}$ \\
\hline Mean bypass time & $163 \pm 37.2 \mathrm{~min}$ \\
\hline
\end{tabular}

\section{Results}

\begin{tabular}{|l|c|}
\hline Mortality & $3(12 \%)$ \\
CABG+MVR & $1(6.6 \%)$ \\
CABG+AVR & $1(12 \%)$ \\
CABG+DVR & $1(50 \%)$ \\
\hline Low Cardiac output syndrome & $4(16 \%)$ \\
\hline Re- exploration & $1(4 \%)$ \\
\hline Wound infection/sepsis & $3(9 \%)$ \\
\hline Renaldysfunction & $2(8 \%)$ \\
\hline
\end{tabular}

$\begin{array}{lc}\text { LESION } & \text { No of patients } \\ \text { Mitral valve } & 15 \\ \text { Stenosis } & 7 \\ \text { Regurgitation } & 2 \\ \text { Mixed } & 6 \\ \text { Aortic valve } & 8 \\ \text { Stenosis } & 5 \\ \text { Regurgitation } & 1 \\ \text { Mixed } & 2 \\ \text { Combined lesion } & 2 \\ \text { SVD } & 8 \\ \text { DVD } & 13 \\ \text { TVD } & 4\end{array}$

\section{Operative Technique}

All operations were done via median sternotomy approach. standard cardiopulmonary bypass techniques with moderate hypothermia and cardioplegic arrest were used. Distal coronary anastomosis was done using either internal mammary artery or saphenous vein grafts. All except two valve replacements were performed using St Jude Medical regent valve (SJM) (St Jude Medical, St Paul, Minn) with pledgetted interrupted sutures. Carpentiers-Edwards Perimount Magna EaseBioprosthesis (Edwards Life sciences, Irvine, CA, USA) was implanted in one patient and Hancock II valve (Medtronic Inc, Minneapolis, MN) in rest of the patients. Proximal grafts were applied on beating heart with aorta clamped partially. Patients were shifted to intensive care with or without inotropic support as and when required. They were extubated as early as possible and anticoagulation was started with ecosprin and warfarin.

\section{Results}

Most common surgical procedure performed was CABG+MVR (60\%) followed by $\mathrm{CABG}+\mathrm{AVR}$ $(32 \%)$ and CABG+DVR (8\%). Total no of grafts applied were $46(1.91 \pm 0.69)$. LIMA was used to anastomose LAD in 19 cases (41.3\% of grafts). Right coronary was bypassed in 14 cases $(30.4 \%$ Of grafts) and left circumflex was bypassed in 13 cases $(28.2 \%$ of grafts). Mean cross clamp time was $116.1 \pm 23.3$ mins and mean bypass time was $163 \pm 37.2$ mins. 
Overall perioperative mortality was $12 \%(n=3)$. Mortality in patients who underwent CABG+ MVR was $(\mathrm{n}=1 ; 6.6 \%), \mathrm{CABG}+\mathrm{AVR}$ was $(\mathrm{n}=1$; $12 \%)$ and $\mathrm{CABG}+\mathrm{DVR}$ was $(\mathrm{n}=1 ; 50 \%)$. All three patients who did not survive showed features of low cardiac output.Preoperatively these patients had severe pulmonary artery hypertension $(n=1)$, congestive heart failure $(n=2)$ and triple vessel coronary artery disease with type 2 diabetes mellitus(n=1).

\section{Disscussion}

Bozbas et al performed angiography in all patients above 40 years of age and also in patients with clinical suspicion of CAD. They reported angina pectoris was present only in seven patients out of 41 in less than 50 years of age where the youngest patient was a 40-year-old male. Hence, they concluded that CAG can be omitted in patients below the age of 40 if there is no angina or coronary risk factors. They also reported that patients with CAD have significantly increased prevalence of diabetes, hypertension, history of smoking, and family history of CAD. ${ }^{[5]}$

In 1980, Morrison et al performed elective CAG in adult patients and concluded that asymptomatic significant coronary lesion exists in $33 \%$ of patients who were of more than 45 years of age group scheduled for valve replacement. The peri-operative mortality (within 4 weeks of valve replacement) with combined $\mathrm{CABG}$ was higher $(20 \%)$ as compared with valve replacement alone (5.9\%). They concluded that as there are no adequate clinical markers of CAD in patients with valvular heart disease, routine CAG should be a part of the pre-operative investigation, but there was no data to recommend the lower age limit ${ }^{[6]}$. In our institute we routinely do elective coronary angiography in all the patients of valvular heart disease who are above 40 years of age or who have symptoms of coronary artery disease.

The operative mortality of patients undergoing MVR and CABG has been higher than those undergoing AVR and CABG. In early days, the mortality has been reported to be as high as $19 \%^{[7]}$ in patients undergoing MVR (rheumatic and degenerative) and $30 \%{ }^{[8]}$ in patients with ischemic MR. This has been explained on the basis of poor functional class, severe MR-related volume overloaded ventricle and its failure to resume adequate function after a prolonged combined procedure, unstable ischemia, extensive CAD, compromised left ventricular function, and an elevated pulmonary vascular resistance. In combined AVR and CABG, LV dysfunction has been reported to be a risk factor ${ }^{[9]}$.The increase in mortality in the AS group could be related to a smaller aortic valve size, higher mean age, female patients, and that the AS group may have increased subendocardial ischemia rates related to CAD with LV hypertrophy.

With improvements in myocardial protection techniques results have improved significantly. Recent studies reported an early mortality of 2- $11 \%$ for concomitant AVRand CABG ${ }^{[10-13]}$ and $8-11 \%$ for concomitant MVR and $\mathrm{CABG}^{[13,14]}$. In the latest study by Nassir and colleagues, perioperative mortality of concomitant AVR and CABG was almost equal to AVR alone but 5years survival of valve plus CABG patients were significantly higher than that of AVR alone $^{[15]}$. In our study overall mortality was $12 \%$ which is comparable to the previously published results.

In 2018 ESC/EACTS guidelines, CABG is a class I recommendation for patients with primary indication of aortic/mitral valve surgery and coronary artery diameter stenosis $>70 \%$ and class IIa recommendation for coronary artery diameter stenosis $50-70 \%$.

It has been reported that the short-term mortality of concomitant DVR is considerable and concomitant CABG has adverse effects on the survival of patients with valve replacement surgery. The overall survival predictors in most studies were age, cerebrovascular accident and balloon pump insertion, while the independent predictors of overall survival were cigarette smoking, age, chronic kidney diseases and balloon pump insertion in our multivariate analysis. Age, 
NYHA class III-IV, congestive cardiac failure, paroxysmal nocturnal dyspnoea, pulmonary artery hypertension, preoperative left ventricular ejection fraction $<50 \%$, left atrial size, cardiomegaly, associated surgeries, renal dysfunction, mean right atrial pressure $>14 \mathrm{mmHg}$ and mean pulmonary artery wedge pressure $>24 \mathrm{mmHg}$ were the independent predictors of late survival after $\mathrm{DVR}^{[16]}$. In the latest study of CABG plus DVR done by Davarpasand and colleagues, the in hospital mortality was $7 \%$ which is much lower than mortality of DVR in our series $(50 \%) .{ }^{[17]}$ But this may be attributed to very few patients of DVR $(n=2)$ in our study sample. Out of the 2 patients, one was critically ill with triple vessel diseases, type2 diabetes with low ejectionFraction and NYHA IV.

Pulmonary artery hemodynamic, especially pulmonary vascular resistance, can affect early mortality and late survival after combined MVR and CABG. Rheumatic mitral disease is a chronic condition and most patients have extremely high pulmonary artery pressure and pulmonary vascular resistance. Preoperative High pulmonary vascular resistance and higher NYHA class with poor left ventricular function have been established risk factors for early mortality ${ }^{[18,19]}$. In our study, the patients with the above risk factors also had similar poor outcome. All the patients who died or developed postoperative complications were NYHA III-IV or presented with features of congestive heart failure.

Gender, number of grafts and type of prosthesis did not affect survival but patients with adverse outcome had significantly higher cross-clamp and bypass time in our study. But as we had very few cases in our study it was difficult to conclude on the effect of these factors.

Hence among patients who undergo concomitant CABG and valve surgery, especially those who have severe Aortic stenosis (hypertrophied Left Ventricle), the prognosis in terms of mortality can be alarming and that the myocardial protection during the procedure should be taken care of (by way of inclusion of warm cardioplegia, retrograde cardioplegia, continuous perfusion, and the inclusion of various additives that aim at reducing $\mathrm{Ca}^{2}+$ overload, provide energy substrates, and remove harmful reactive oxygen species).

\section{Limitation of the Study}

The sample size was small in our study, therefore multiple confounding factors could not be eliminated to establish the outcomes of surgery.

\section{Conclusion}

All patients above 40 years of age should be screened for coronary artery disease by an angiogram. CABG should be performed whenever graftable lesions are present in a patient with primary indication of aortic/mitral valve. Adequate myocardial preservation should be done during the procedure.

\section{Bibliography}

1. Karp RB, Millis N, Edmunds LH. Coronary artery bypass grafting in the presence of valvular disease. Circulation 1989;79(Suppl I):I-182-4.

2. Lytle BW. Impact of CAD on valvular heart surgery. Cardiol Clin 1991;9:301-14.

3. Flemma RJ, Johnson WD, Lepley D Jr, Auer JE, TectorAJ, Blitz J. Simultaneousvalve replacement and aortato-coronarysaphenous vein bypass. Ann ThoracSurg1971;12:163-70.

4. Wisoff BG, Fogel R, Weisz D, Garvey J, Hamby R.Combined valve and coronary artery surgery. Ann ThoracSurg 1980;29:440-3.

5. Bozbaş H, Yildirir A, Küçük MA, Ozgül A, Atar I, Sezgin A, et al.Prevalence of coronary artery disease in patients undergoing valvularoperation due to rheumatic involvement. Anadolu Kardiyol Derg2004;4:223-6.

6. Morrison GW, Thomas RD, Grimmer SF, Silverton PN, Smith DR. Incidence of coronary artery disease in patients with 
valvular heart disease. $\mathrm{Br}$ Heart $\mathrm{J}$ 1980;44:630-7.

7. Kabbani SS, Bashour TT, Hanna ES, Ellertson D. Risk of combined coronary artery bypass and mitral valve replacement. Tex Heart Inst J 1984;11:348-51.

8. Kirklin JK, Naftel DC, Blackstone EH, Kirklin JW, Brown RC. Risk factors for mortality after primary combined valvular and coronary artery surgery. Circulation 1989;79:I185-90.

9. Mehta RH, Bruckman D, Das S, Tsai T, Russman P, Karavite D, et al. Implications of increased left ventricular mass index on in-hospital outcomes in patients undergoing aortic valve surgery. J Thorac Cardiovasc Surg 2001;122:919-28

10. Gunay R, Sensoz Y, Kayacioglu I, Tuygun AK, Balci AY, Kisa U, et al. Is the aortic valve pathology type different for early and late mortality in concomitant aortic valve replacement and coronary artery bypass surgery? Interact Cardiovasc Thorac Surg 2009;9:630-4.

11. Herlitz J, Brandrup-Wognsen G, Caidahl K, Haglid M, Karlsson BW, Karlsson T, et al. Mortality and morbidity among patients who undergo combined valve and coronary artery bypass surgery: Early and late results. Eur J Cardiothorac Surg 1997;12:836-46.

12. Folkmann S, Gorlitzer M, Weiss G, Harrer $\mathrm{M}$, Thalmann $\mathrm{M}$, Poslussny $\mathrm{P}$, et al. Quality-of-life in octogenarians one year after aortic valve replacement with or without coronary artery bypass surgery. Interact Cardiovasc Thorac Surg 2010;11:750-3.

13. Kobayashi KJ, Williams JA, Nwakanma L, Gott VL, Baumgartner WA, Conte JV. Aortic valve replacement and concomitant coronary artery bypass: Assessing the impact of multiple grafts. Ann Thorac Surg 2007;83:969-78.

14. Sirivella S, Gielchinsky I. Results of coronary bypass and valve operations for mitral valve regurgitation. Asian Cardiovasc Thorac Ann 2007;15:396-404.

15. Thalji NM, Suri RM, Daly RC, Greason KL, Dearani JA, Stulak JM, Joyce LD, Burkhart HM, Pochettino A, Li Z, Frye RL. The prognostic impact of concomitant coronary artery bypass grafting during aortic valve surgery: implications for revascularization in the transcatheter era. The Journal of thoracic and cardiovascular surgery. 2015 Feb 1;149(2):451-60.

16. Panda BR, Shankar R, Kuruvilla KT, Philip MA, Thankachen R, Shukla Vet al. Combined mitral and aortic valve replacement for rheumatic heartdisease:fifteen-year follow up and long-term results. J Heart Valve Dis2009;18:170-9.

17. Davarpasand T, Hosseinsabet A, Jalali A. Concomitant coronary artery bypass graft and aortic and mitral valve replacement for rheumatic heart disease: shortand midterm outcomes. Interactive cardiovascular and thoracic surgery. 2015 May 29;21(3):322-8.

18. Kay PH, Nunley DL, Grunkemeier GL, Pinson CW, Starr A. Late results of combined mitral valve replacement and coronary bypass surgery. J Am Coll Cardiol 1985;5:29-33.

19. Gehlot A, Mullany CJ, Ilstrup D, Schaff HV, Orzulak TA, Morris JJ, et al. Aortic valve replacement in patients aged eighty years and older: early and long-term results. J Thorac Cardiovasc Surg 1996;111:1026-36. 